\title{
Educação e Qualidade de Vida de Idosos: \\ Uma Reflexão Necessária
}

\author{
Fátima Niemeyer da Rocha \\ Universidade Severino Sombra, CECS, fatimaniemeyer@uol.com.br \\ Maria Elisa Carvalho Bartholo \\ Universidade Severino Sombra, CELCSAH, elisacbar@yahoo.com.br
}

\begin{abstract}
Resumo: A qualidade de vida do idoso vem assumindo grande importância, sob vários aspectos, principalmente em função do envelhecimento crescente da população, decorrente do aumento da expectativa de vida gerada pelos desenvolvimentos na área da saúde e no setor tecnológico, refletindo uma sensível modificação na quantidade e na qualidade de vida de grande parte das pessoas. Assim, o presente artigo discute a questão do envelhecimento na atualidade e a necessidade de implementação da educação continuada do idoso no âmbito da universidade, frente à possibilidade de realização de ações efetivas de responsabilidade social, como alternativa para minimizar os efeitos da exclusão social desse grupo etário.
\end{abstract}

Palavras-chave: Educação. Qualidade de Vida. Idosos.

\section{Education And Quality In Elderly Life:}

\section{A Needed Reflection}

\begin{abstract}
The quality of life in elderly has taken on great importance in several respects, mainly due to the increasing aging population, due to increased life expectancy generated by developments in health and in technology sector, reflecting a significant change in the quantity and quality of life for most people. Thus, this article discusses the issue of aging in the present and the need to implement the continuing education of the elderly into the university, facing the possibility of realization of effective social responsibility, as an alternative to minimize the effects of social exclusion in this age group.
\end{abstract}

Keywords: Education. Quality of Life. Elderly.

\section{Introdução}

Mosaico - Revista Multidisciplinar de Humanidades, Vassouras, v. 1, n. 2, p. 21-36, jul./dez., 2010 
Dossiê Temático:

Cultura, Civilização e Cidadania

O envelhecimento da população é um fenômeno relativamente novo e de amplitude mundial. A Organização Mundial da Saúde (OMS) classifica como idosos as pessoas com mais de 65 anos de idade em países desenvolvidos e com mais de 60 anos de idade em países em desenvolvimento, e projeta que em 2025 existirão 1,2 bilhões de pessoas com mais de 60 anos, sendo que os muito idosos - isto é, com 80 ou mais anos constituem o grupo etário de maior crescimento [OMS, 2001]. A expectativa de vida (para ambos os sexos, no nascimento) do mundo era de 66,57 anos (64,52 anos para os homens e 68,76 anos para as mulheres) em 2009, segundo o The World Factbook [CIA, 2009], e de 67,2 anos (65,0 anos para os homens e 69,5 anos para as mulheres), de acordo com o relatório de Perspectivas da População Mundial das Nações Unidas, para o período de 2005-2010 [United Nations, 2007]. No Brasil, um indicador que mostra o processo de envelhecimento da população é o índice de envelhecimento - em 2000, para cada grupo de 100 crianças de 0 a 14 anos, havia 18,3 idosos de 65 anos ou mais; em 2050, a relação poderá ser de 100 para 105,6. Além disso, se em 2000, eram 1,8 milhão de pessoas com 80 anos ou mais de idade e, em 2050, poderão ser 13,7 milhões de pessoas na mesma faixa etária. [Oliveira, Albuquerque e Lins, 2004]

Nessa perspectiva, nos últimos anos a questão da qualidade de vida do idoso vem assumindo uma grande importância, sob vários aspectos. A qualidade de vida abrange muitos significados que refletem os conhecimentos, as experiências e os valores, tanto de indivíduos quanto de coletividades, e tais significados exprimem o momento histórico, a classe social e a cultura as quais pertencem. A qualidade de vida de uma população tem sido avaliada também a partir do atendimento da necessidade da educação permanente do idoso, tendo em vista o fato de estarmos vivendo na era da informação, que tem reivindicado ações socialmente responsáveis e efetivas que coloquem ênfase numa educação libertadora para que o idoso possa ter acesso ao saber e ser cidadão.

Além disso, o Estatuto do Idoso (Lei 10.741/2003), destinado a regular os direitos assegurados às pessoas com idade igual ou superior a 60 anos no Brasil, estabelece, no seu Art. $2^{\circ}$, que

O idoso goza de todos os direitos fundamentais inerentes à pessoa humana, sem prejuízo da proteção integral de que trata esta Lei, assegurando-se-lhe, por lei ou por outros meios, todas as oportunidades e facilidades, para preservação de sua saúde física e mental e seu aperfeiçoamento moral, intelectual, espiritual e social, em condições de liberdade e dignidade. [Brasil, 2003]

Também, no seu Art. $3^{\circ}$, determina que

É obrigação da família, da comunidade, da sociedade e do Poder Público assegurar ao idoso, com absoluta prioridade, a efetivação do direito à vida, à saúde, à alimentação, à educação, à cultura, ao esporte, ao lazer, ao trabalho, à cidadania, à liberdade, à dignidade, ao respeito e à convivência familiar e comunitária. [Brasil, 2003] 
Dossiê Temático:

Cultura, Civilização e Cidadania

Ainda, em seu Art. 20, o estatuto estabelece que "O idoso tem direito à educação, cultura, esporte, lazer, diversões, espetáculos, produtos e serviços que respeitem sua peculiar condição de idade." E, no Art. 21, que "O Poder Público criará oportunidades de acesso do idoso à educação, adequando currículos, metodologias e material didático aos programas educacionais a ele destinados.” [Brasil, 2003]

No momento atual, a universidade é uma instituição que apresenta a estrutura e o equipamento adequados para responder as necessidades educacionais do idoso, através da estruturação de micro universidades temáticas voltadas para a terceira idade, onde o idoso, além de receber assistência e participar de atividades culturais e de lazer, pode constituir um campo "para pesquisas em várias áreas do conhecimento, ajudando na formação de profissionais de alta qualificação e alavancando a produção de conhecimento sobre o envelhecimento humano" [Veras e Caldas, 2004]. O movimento das Universidades da Terceira Idade vem tendo um incremento significativo desde a década de 1970, com a difusão de conceitos e experiências práticas relativas a uma "nova forma de promover a saúde da pessoa que envelhece, a partir de uma ação interdisciplinar comprometida com a inserção do idoso como cidadão ativo na sociedade." [Veras e Caldas, 2004] Utilizando as possibilidades existentes nas universidades, esse movimento tem o objetivo de contribuir para a promoção da saúde física, mental e social das pessoas idosas.

No ano de 2004, no Brasil, já existiam pelo menos 150 programas dessa natureza, cujos resultados têm sido sistematizados e debatidos, trazendo novas perspectivas de inserção e ampliação da participação social e da melhoria das condições de saúde, e qualidade de vida dos seus participantes. Tendo como pressupostos básicos a interdisciplinaridade, a participação social e a promoção da saúde, as propostas das Universidades da Terceira Idade têm utilizado uma metodologia adaptada às especificidades desta clientela na elaboração de um programa amplo de atenção integral ao idoso. [Veras e Caldas, 2004] A educação do idoso é, sem dúvida, uma das possibilidades que se apresentam para a universidade de realização de ações efetivas no âmbito da responsabilidade social, na medida em que propicia sua participação na comunidade, como alternativa para minimizar os efeitos da exclusão social. Além disso, reforça seu compromisso ético com o desenvolvimento humano, transcendendo o simples gesto de filantropia para se incorporar à sua missão, seus valores e suas estratégias de ação educacional. Além disso, a Universidade Aberta da Terceira Idade contribui para a transformação do autoconceito sobre a velhice e a população idosa que participa de programas voltados para a sua educação, que apresenta visíveis mudanças em sua qualidade de vida, não apenas em termos individuais, mas também sociais.

\section{Da Qualidade de Vida}

Se, por um lado, a idéia de qualidade de vida é, frequentemente, relacionada à aquisição de bens materiais e ao seu impacto na vida das pessoas [Qualidade de vida, 2002], por outro, em decorrência do crescente desenvolvimento tecnológico da medicina e ciências afins, que trouxe como consequiência negativa a sua progressiva desumanização, a preocupação com o conceito de qualidade de vida passou a referir-se a um movimento dentro das ciências humanas e biológicas no sentido de valorizar parâmetros mais 
Dossiê Temático:

Cultura, Civilização e Cidadania

amplos que o controle de sintomas, a diminuição da mortalidade ou o aumento da expectativa de vida [WHOQOL, 1998]. Em 1958, a OMS definiu saúde como um "estado de completo bem-estar físico, psíquico e social e não apenas a ausência de doença ou enfermidade" e, no final da década de 1970, a preocupação com o tema passou a ocupar um espaço cada vez maior nos relatórios da própria OMS e fazer parte das preocupações acadêmicas, em todo o mundo.

Os relatórios da OMS apontam para algumas tendências da população geral face à busca de qualidade de vida, tais como fugir progressivamente dos grandes aglomerados urbanos, a luta por semanas de trabalho mais curtas e a retomada da vida em família, entre outras. E em 1988 a Constituição Brasileira legitimou a saúde para o cumprimento de uma série de direitos de cidadania com qualidade de vida [Qualidade de vida, 2002]. Por ser um tema de grande atualidade, a qualidade de vida tem sido objeto de inúmeros estudos cujos autores, no entanto, partem de posições diversas [Bobes, Cervera, Seva, 1995] e diferentes países têm centrado os estudos em relação à qualidade de vida em grupos particulares, como, por exemplo, pessoas enfermas, grupos homogêneos como anciãos, mulheres etc. [Baca, 1997]. Embora alguns autores apontem para a possibilidade de que o conceito de qualidade de vida possa ser dissociado da cultura [Fox-Rushby e Parquer, 1995 apud WHOQOL, 1998], outros têm considerado a existência de um "universal cultural" de qualidade de vida, onde o importante é que as pessoas se sintam bem psicologicamente; isto é, possuam boas condições físicas e sintam-se socialmente integradas e funcionalmente competentes [Bullinger, 1993 apud WHOQOL, 1998].

A diversidade de abordagens e concepções gerou a necessidade de unificar critérios e posições, tendo partido da própria OMS, em 1994, através de seu Grupo de Qualidade de Vida - The WHOQOL Group, da divisão de Saúde Mental -, a proposta de uma definição de consenso de qualidade de vida, como: "a percepção pessoal de um indivíduo de sua situação na vida, no contexto da cultura e sistema de valores nos quais vive, e em relação aos seus objetivos, expectativas, valores e interesses" [Bobes, Cervera e Seva, 1995; Vázquez-Varquero et al 1998; Lucas, 1998; WHOQOL, 1998], incluindo seis domínios principais: saúde física, estado psicológico, níveis de independência, relacionamento social, características ambientais e padrão espiritual [Dantas, Sawada e Malerbo, 2003]. E destacam-se três aspectos referentes ao seu constructo: subjetividade, multidimensionalidade e presença de dimensões positivas (como mobilidade) e negativas (como dor) [WHOQOL Group, 1994 apud WHOQOL, 1998].

Nesse sentido, a qualidade de vida reflete a percepção dos indivíduos de que suas necessidades estão sendo satisfeitas ou de que lhes estão sendo negadas oportunidades de alcançar a felicidade e a auto-realização, com independência de seu estado de saúde físico ou das condições sociais e econômicas. [Pereira et al, 2006] Sobre as novas demandas presentes no mundo atual, Diskin [2000 apud Gáspari e Schwartz, 2005] alerta para o fato de que a qualidade de vida, nos níveis individual e coletivo, está diretamente condicionada às oportunidades de conhecimento e escolha de uma gama de valores, os quais nem sempre pertencem à sociedade onde o ser humano se acha inserido: a qualidade de vida pessoal, institucional ou social depende em grande escala da capacidade de se relacionar com o outro (o diferente), o entorno e o planeta de 
Dossiê Temático:

Cultura, Civilização e Cidadania

maneira respeitosa e responsável, promovendo o legítimo direito de oportunidades para usufruir os bens naturais e culturais que todas as comunidades humanas têm disponibilizado ao longo da nossa história.

Forattini [1991 apud Qualidade de vida, 2002] enfatiza uma concepção social da qualidade de vida, para a qual há vários indicadores: ambientais - qualidade da água, do ar e do solo, domesticação e domiciliação, acidentalidade; habitacionais disponibilidade espacial e condições de habitação; urbanos - concentração populacional, comunicação, transporte, segurança, poluição; sanitários - assistência médica, morbidade, mortalidade; sociais - sistemas de classes, nível sócio-econômico, consumo, necessidades, sexualidade, condições de trabalho, lazer, sistema político-administrativo. E Hornquist [Forattini, 1991 apud Qualidade de vida, 2002] destacou como determinantes de qualidade de vida: aspectos orgânicos - saúde e estado funcional; aspectos psicológicos - identidade, auto-estima, aprendizado; aspectos sociais relacionamento, privacidade, sexualidade; aspectos comportamentais - hábitos, vida profissional, lazer; aspectos materiais - economia privada, renda, habitação; aspectos estruturais - posição social, significado da própria vida.

Do ponto de vista dos grupos etários, os resultados dos estudos demonstram que, apesar dos grupos hierarquizarem os fatores que mais influem na qualidade de vida em ordens diferentes, existe um elemento comum: o lazer, o qual representa um papel importante na qualidade de vida do ser humano, ao permitir o relaxamento e o desfrutar do tempo livre, propiciando uma sensação de bem-estar. Devido ao aumento da expectativa de vida, a qualidade de vida da população idosa passou a obter lugar de destaque, principalmente na área da saúde. Os estudos de qualidade de vida, em geral, têm definido como problemas: como a população percebe a qualidade de vida, como a define, quais as opiniões e critérios com relação ao tema, como se percebe a qualidade de vida em áreas com condições de vida diferentes, entre outros. E têm assinalado elementos comuns como: lazer, saúde, economia, vínculo funcional, redes de apoio familiar e/ou social, auto-estima e otimismo. Para os anciãos, entre os elementos mais importantes têm sido enfatizados: a rede de apoio, a saúde e o lazer. Este grupo admite que a saúde vai declinando e, por isso, o apoio externo se converte no elo fundamental para manter a qualidade de vida. Para os idosos, a qualidade negativa de vida aparece relacionada, em geral, com a perda de saúde e a qualidade de vida positiva, com uma pluralidade de categorias como atividade, renda, vida social e relação com a família. [Xaviera, Ferraz, Marc, 2003].

Em geral, o conceito de qualidade de vida está centrado no aspecto subjetivo, ou seja, as populações estudadas têm avaliado a qualidade de vida em termos de bem-estar, satisfação, alegrias, expectativas e felicidade percebida; nesse sentido, os idosos se referem à aceitação de suas limitações. E Bosq (2001) argumenta que a qualidade de vida é um conceito subjetivo, relacionado com a percepção que se tem acerca da própria vida, no sentido de sentir-se realizado com o próprio ser. 


\section{Dos Idosos}

As teorias do envelhecimento bem sucedido vêem o sujeito como proativo, regulando a sua qualidade de vida através da definição de objetivos e lutando para alcançá-los, acumulando recursos que são úteis na adaptação à mudança e ativamente envolvidos na manutenção do bem-estar. O envelhecimento bem sucedido é, assim, acompanhado de qualidade de vida e bem-estar e deve ser fomentado ao longo dos estágios anteriores de desenvolvimento. [Souza, Galante e Figueiredo, 2003]. Especificamente na velhice, a qualidade de vida tem sido, muitas vezes, associada a questões de dependênciaautonomia. As dependências observadas nos idosos resultam tanto de alterações biológicas (deficiências ou incapacidades), como de mudanças nas exigências sociais (desvantagens) e, frequentemente, as últimas parecem determinar as primeiras. Com relação às dependências, Baltes e Silvenberg (1995) descrevem três tipos: dependência estruturada - onde o significado do valor do ser humano é determinado pela participação no processo produtivo (na velhice, salienta-se a dependência gerada pela perda do emprego); dependência física - incapacidade funcional individual para realizar atividades de vida diária; e dependência comportamental - com frequência antecedida pela dependência física, é socialmente induzida, independentemente do nível de competência do idoso.

Diversas são as teorias explicativas sobre o ciclo de vida e a adaptação do ser humano ao processo de envelhecimento. Desde a década de 1950, os pesquisadores da área social têm delineado amplas questões teóricas acerca das mudanças resultantes do envelhecimento. Com o objetivo de estruturar de uma maneira compreensiva a posição dos velhos na sociedade, a teoria da desvinculação considera que durante o processo de envelhecimento a pessoa experimenta uma separação gradual da sociedade, um decréscimo na interação com seu meio ambiente, que se acentua com a modernização da sociedade. Este retraimento da vida social se manifesta, especialmente, no caso da aposentadoria, como um referente fundamental de seu afastamento da vida produtiva. No pólo oposto ao da teoria da desvinculação, a teoria da atividade argumenta que quanto maior for o número de atividades que o idoso realize, maiores são as possibilidades de se sentir satisfeito com a vida. Esta teoria se fundamenta na premissa de que todos os seres humanos desenvolvem seus valores, significados e modos de atuação a partir de um processo de comunicação social. Segundo a teoria da continuidade a diminuição na realização das diferentes atividades do idoso pode ser explicada em função da saúde empobrecida ou de incapacidade adquirida e não por uma necessidade funcional de desvincular-se, sentida pela pessoa, que tenderá mais a continuar do que a mudar, sempre que as demais condições permaneçam estáveis. A continuidade interna se refere a uma evolução gradual na qual se unem e se criam direções novas na identidade já existente. Já a teoria da subcultura considera que as pessoas idosas formam uma subcultura própria que se modela na organização de importantes grupos de pressão, como as associações de aposentados. Embora sendo mais um marco conceitual do que uma teoria, a perspectiva do ciclo de vida tem sido utilizada para realizar investigações sobre normas segundo a idade, percepção da idade e momentos de transição. Essa perspectiva incorpora hipóteses sobre o papel das normas sociais sobre a conduta e parte da idéia de que o envelhecimento é um processo de evolução que se inicia com o próprio nascimento e cuja experiência varia em 
Dossiê Temático:

Cultura, Civilização e Cidadania

função de fatores históricos. A teoria da modernização pretende explicar as mudanças no status da pessoa idosa a partir das modificações ocorridas nos sistemas sociais, em função do grau de industrialização que alcançam as diferentes sociedades, onde o nível do status do idoso é inversamente proporcional ao grau de industrialização. [FernandezBallesteros apud Dias, 2005]

Já a teoria dos grupos de interesse chama a atenção para o fato das próprias políticas públicas terem ajudado a criar grupos de interesse baseados na idade, os quais pressionam os decisores políticos a darem respostas às suas necessidades. A teoria dos papéis argumenta que a perda de papéis funcionais decorrente do envelhecimento é vista como algo inevitável e concomitante da modernização. Encarando o desenvolvimento como um processo que se dá ao longo de todo o ciclo de vida, a teoria do desenvolvimento considera o desenvolvimento humano como qualitativo, irreversível e universal, onde ocorrem processos de continuidade/descontinuidade, é multidirecional, está sujeito a equilíbrios entre ganhos e perdas, sendo contingente às condições culturais, históricas, ambientais e ao ritmo das mudanças. Ao considerar que o envelhecimento também deriva do comportamento individual, a teoria econômica e da escolha racional parte das premissas de que os indivíduos tendem a maximizar as recompensas em detrimento dos custos e interagem também com a finalidade de obterem benefícios máximos para todos. De acordo com a teoria da troca os idosos possuem poucos recursos e, em decorrência, dificilmente podem contribuir para as trocas intergeracionais. [Marshall apud Dias, 2005]

Analisando o processo que vem presidindo a construção social da velhice no Brasil, Debert (2004) demonstra que o idoso é um ator não mais ausente do conjunto de discursos produzidos, estando presente no debate sobre políticas públicas, nas interpelações dos políticos em momentos eleitorais e até mesmo na definição de novos mercados de consumo e novas formas de lazer. Os integrantes do que se convencionou chamar de "terceira idade" crescem a cada ano e já são uma porção considerável da nossa população, o que coloca para as famílias, para as empresas e para o governo questões que não podem deixar de ser respondidas.

Côrte, Mercadante e Arcuri (2005), chamando a atenção para questões sociais, culturais e psicológicas presentes no processo de envelhecimento, argumentam que em nossa cultura não existe uma idéia clara do ciclo da vida, pois o indivíduo recebe um intenso treinamento para apenas metade da vida e, depois de ter estudado, se profissionalizado, casado, tido filhos, se aposentado etc., não sabe o que fazer com os próximos 10, 20, 30 ou 40 anos de existência. Não há orientação sobre essa etapa da vida que, doravante, será o tempo mais longo de sua existência. Apontam para a metanóia, isto é, a transformação que ocorre na segunda metade da vida, na qual há possibilidade de mudanças de valores, em que o mundo interior passa a ter prevalência sobre o exterior e onde o Self pode ter sua livre expressão, resultando em criatividade. Para Monteiro [Côrte, Mercadante e Arcuri, 2005], viver é envelhecer e envelhecer é viver. A vida gera, alimenta, consome e nos entrega à morte; assim, durante o processo de viver passamos por constantes ciclos de renovação, que nos propicia o envelhecer. "Quanto mais vivermos, mais velhos estaremos" e, embora muitas pessoas almejem o "modelo de juventude sempiterna", ninguém pode escapar do processo natural do envelhecer. E Almeida [Côrte, Mercadante e Arcuri, 2005] aponta para o grande hiato que 
Dossiê Temático:

Cultura, Civilização e Cidadania

separa a realidade de tudo que é desejável e esperado em relação às condições de vida de muitos dos brasileiros com 60 anos ou mais de idade. Este hiato, de há muito instalado, explicita-se nos mais diversos âmbitos da existência humana, como a saúde, a aposentadoria, as pensões e outros "benefícios", a alimentação, o transporte, o saneamento básico, a acessibilidade etc. Sem minimizar a importância dos projetos de vida e do lugar por eles ocupados na qualidade de vida das pessoas em geral, e dos idosos em particular, alerta para o fato de que o binômio "velhice X projeto de vida" encontra-se ainda aberto a pesquisas e reflexões.

Ao tratar das representações sociais da memória e sua relevância enquanto constitutiva das identidades dos indivíduos e dos grupos, Brandão [Côrte, Mercadante e Arcuri, 2005] coloca o foco nas reflexões sobre a memória afetiva ou cultural. A dinâmica das memórias sócio-afetivas aponta para as possibilidades de rever e ressignificar o passado e seus acontecimentos - bons ou não -, oferecendo novas abordagens para uma revisão dos projetos de vida e trabalho. Em Diogo, Néri e Cachioni (2004) encontramos o argumento de que, mesmo o envelhecimento acarretando o aumento na probabilidade de ocorrência de doenças, de declínio da funcionalidade e de afastamento social, a velhice pode ser marcada por bem-estar físico e psicológico e continuidade das capacidades presentes na vida adulta. $\mathrm{O}$ abandono das idéias de velhice apenas como problema médico-social, dos idosos simplesmente como indivíduos a serem tutelados e do envelhecimento como processo a ser mascarado, apresenta possibilidades de intervenções destinadas a manter e a recuperar a sua independência funcional e a sua autonomia, quando comprometidas por doenças e por fatores de risco ambientais e associados à subjetividade. Monteiro (2001) demonstra como foi possível a mulheres idosas, com crescentes deficiências físicas, conseguirem mudar sua auto-imagem, seu corpo e sua história pessoal, enfrentando o paradoxo da idade, descobrindo novos caminhos para suas jornadas e percebendo o valor de seus corpos, há muitos anos anestesiados para a vida. Abordando as experiências de isolamento dos idosos, de distanciamento do próprio corpo e da falta de toque e de afeto, demonstra que envelhecer também pode ter um significado diferente do convencional, caracterizado pela falta de atividade produtiva e pela valorização excessiva das limitações físicas, que acabam por inibir a auto-estima e ampliar a depressão, e que cada um pode viver esse processo sem sofrimento, avançando na vida com mais sabedoria e descobrindo novas maneiras de estar no mundo.

Numa ampla reflexão acerca dos direitos do idoso, Braga (2004) entende que o crescimento relativamente elevado do contingente idoso significa mudanças efetivas não só na estrutura etária, mas, sobretudo, nas estruturas familiares e sociais e que, nesse contexto, o idoso precisa construir uma nova identidade social, manter sua autonomia e exercer sua cidadania de tal forma que suas necessidades sejam refletidas em todos os segmentos. Fogaça (2001) descreve uma experiência com o processo de educação para o envelhecimento, numa instituição educacional onde o idoso tem a oportunidade de refletir sobre o seu próprio envelhecimento e o envelhecimento do outro, aprendendo um conceito diferente sobre o envelhecimento e sobre sua própria condição. Demonstra como a pessoa revive, descobre-se e valoriza-se pela possibilidade de mudar seu pensamento, seu comportamento e reversua imagem de velho e da velhice, mudanças que podem tornar o idoso mais valorizado por sua família, não sendo mais 
visto como "velho" (no sentido negativo) nem como um peso para os familiares.

Em Lima (2001a) encontramos a possibilidade de transformação do idoso através da educação permanente, mediante as novas possibilidades de se compreender o cérebro, visto o atual quadro do seu estudo, com as novas contribuições da neurociência sobre a plasticidade cerebral e as suas implicações no processo de envelhecimento e na regeneração cerebral. Focaliza, também, a atual complexidade do mundo e a velhice como problemas sociais, frutos de uma época cheia de progressos tecnológicos, mas muito carente de valores humanitários, e aborda a necessidade da educação permanente, com ênfase na educação libertadora, para os idosos terem acesso ao saber e serem cidadãos. E aponta para a Gerontologia Educacional como possibilidade dessa educação libertadora, com uma metodologia para garantir uma pedagogia do idoso, intencionalmente programada para redirecionar e redimensionar as ações dos idosos em busca de uma velhice consciente e com qualidade de vida e a efetiva transformação dos idosos.

Tendo como ponto de partida o interesse contínuo do ser humano em aprender e se transformar, Kachar (2001) apresenta, na idade da velhice/da maturidade/da terceira idade, o novo aprendiz velho, cujos anos de saber carregam, ambiguamente, a ânsia de aprender e apreender o mundo, transmudando-se com os novos saberes. Descortina a perplexidade diante do novo e aponta para o renascimento provocado pela (re)descoberta do aprender e do conhecer, anunciando o potencial de produção intelectual e do desvelamento da subjetividade em novos encontros consigo, ressignificando papéis e representações sociais. Ferrigno (2004) mostra como o relacionamento entre as diversas faixas etárias tem se modificado ao longo da história recente da civilização ocidental. Na Idade Média, crianças e adultos se misturavam durante as situações de festa ou de trabalho. Ainda hoje, nas comunidades rurais e nas pequenas cidades, esse encontro é mais frequente nas manifestações da cultura popular; já nos grandes centros urbanos, ao contrário, prevalece a separação das gerações em espaços sociais exclusivos. Reafirma a importância da transmissão da memória cultural, que os velhos transmitem aos jovens, e dos modelos de como reagir ao processo de envelhecimento e à proximidade da morte. Por outro lado, o convívio com os jovens desenvolve nos idosos uma maior flexibilidade em relação a novos valores e comportamentos, além de lhes possibilitar um maior acesso às novas tecnologias. Com a aproximação das gerações, que pode incrementar a inclusão social de velhos e jovens, enriquecendo-os mutuamente, desenvolvendo a tolerância e a solidariedade e amenizando os efeitos deletérios do preconceito etário, destaca o estratégico papel desempenhado por agências culturais de ensino informal e propõe a criação de atividades que incentivem esse convívio.

\section{Do Movimento das Universidades da Terceira Idade no Mundo e no Brasil}

A universidade é, tradicionalmente, um espaço dos jovens, onde são gerados novos conhecimentos, um lugar de novidade, e as propostas de Universidade da Terceira Idade não fogem a esse padrão. As Universidades da Terceira Idade, que promovem a saúde e a qualidade de vida do idoso, tomando como pressuposto a saúde como expressão da vida com qualidade, tem como objetivo geral contribuir para a elevação dos níveis 
Dossiê Temático:

Cultura, Civilização e Cidadania

de saúde física, mental e social das pessoas idosas, utilizando as possibilidades existentes nas próprias universidades. [Veras e Caldas, 2004]. Peixoto [1997 apud Veras e Caldas, 2004] afirma que as Universidades da Terceira Idade brasileiras surgiram num momento em que suas similares européias já estavam na terceira geração. A primeira Universidade da Terceira Idade surgiu no final da década de 1960, na França, como um espaço para atividades culturais e sociabilidade, com o objetivo de ocupar o tempo livre e favorecer as relações sociais de idosos. Não havia, então, preocupação com educação permanente, educação sanitária ou assistência jurídica. A segunda geração de Universidades da Terceira Idade surgiu em Toulouse, também na França, em 1973, a primeira voltada para o ensino e a pesquisa. Suas atividades educativas apoiavam-se nos conceitos de participação e desenvolvimento de estudos sobre o envelhecimento. A partir daí as Universidades da Terceira Idade têm sido chamadas a desempenhar o papel de centro de pesquisas gerontológicas. Em 1975, foi criada a Associação Internacional das Universidades da Terceira Idade e, em 1981, havia 59 Universidades da Terceira Idade apenas na França. Em 1980, foi organizada a União Francesa de Universidades da Terceira Idade e, na década de 1980, ainda na França, surgiu a terceira geração das Universidades da Terceira Idade, cujo movimento caracteriza-se pela elaboração de um programa educacional mais amplo, voltado para a oferta de alternativas diversificadas para uma renovada população de aposentados, cada vez mais escolarizada, exigindo cursos universitários formais, com direito a créditos e diploma. [Peixoto, 1997 apud Veras e Caldas, 2004].

De modo geral, as Universidades da Terceira Idade elaboram uma programação baseada em três eixos: participação, autonomia e integração. Com isso, os estudantes passam de simples consumidores a produtores de conhecimento, na medida em que participam das pesquisas universitárias. Os alunos das Universidades da Terceira Idade desempenham um papel ativo nas pesquisas universitárias em três níveis: a) pesquisas feitas para os idosos, para combater os efeitos do envelhecimento; b) pesquisas feitas com os idosos, em que estes mobilizam seus conhecimentos, criatividade, vontade, inteligência e memória, privilegiando discussões em grupo; c) pesquisas feitas pelos idosos, ao adquirir o rigor científico, o espírito crítico e a solidez da reflexão que caracterizam o trabalho universitário e desenvolvem, eles mesmos, seus protocolos de pesquisa. [Peixoto, 1997 apud Veras e Caldas, 2004].

No Brasil, de acordo com Lima [1999 apud Veras e Caldas, 2004], a Universidades da Terceira Idade da Universidade Federal de Santa Catarina iniciou suas atividades em 1983, a partir da criação do seu Núcleo de Estudos da Terceira Idade. Em 1990, em parceria com o SESC, a PUC de Campinas criou sua Universidade da Terceira Idade, a primeira a ser divulgada na mídia em caráter nacional. A partir da década de 1990 partindo das experiências francesas e das diretrizes emanadas do Plano Internacional de Ação sobre Envelhecimento, das Nações Unidas, estabelecido a partir da Primeira Assembléia Mundial sobre o Envelhecimento, realizada em 1982, em Viena, várias Universidades da Terceira Idade foram implantadas pelo país. A Primeira Assembléia Mundial sobre o Envelhecimento, conforme Palma [2000 apud Veras e Caldas, 2004], destacou a necessidade de educação permanente, ou seja, que deve se estender por toda a vida. O Plano Internacional de Ação sobre o Envelhecimento estabelecido nesta assembléia sublinha o descaso dos governos para com os idosos, uma vez que 
Dossiê Temático:

Cultura, Civilização e Cidadania

reservam exclusivamente à criança e ao adolescente os benefícios da educação. O plano recomenda que se assegurem às pessoas que deixam a vida ativa os instrumentos necessários à manutenção da capacidade psíquica e intelectual e sua participação na vida coletiva. A partir de então, ainda segundo Palma [2000 apud Veras e Caldas, 2004], multiplicaram-se os programas voltados para idosos nas universidades brasileiras, com diferentes denominações e seguindo os mais diversos modelos, mas com propósitos comuns, como o de rever os estereótipos e preconceitos com relação à velhice, promover a auto-estima e o resgate da cidadania, incentivar a autonomia, a independência, a auto-expressão e a reinserção social em busca de uma velhice bemsucedida. Atualmente, no Brasil, instituições com estas características somam mais de 150 unidades [Martins de Sá, 1999 apud Veras e Caldas, 2004].

\section{Considerações Finais}

O processo de envelhecimento, que nos países desenvolvidos ocorreu de forma gradual, acompanhado de melhorias na cobertura do sistema de saúde, nas condições de habitação, saneamento básico, trabalho e alimentação, no Brasil ocorre rapidamente e num contexto de desigualdades sociais, economia frágil, crescentes níveis de pobreza, com precário acesso aos serviços de saúde e reduzidos recursos financeiros, sem as modificações estruturais que respondam às demandas do novo grupo etário emergente. [Pereira et al, 2006] A pessoa idosa, segundo Gáspari e Schwartz (2005), enfrenta uma verdadeira crise de identidade durante a qual é afetada em sua auto-estima positiva e na aceitação de si mesma. Numa reação em cadeia, o rebaixamento da auto-estima e as inseguranças quanto à identidade refletem-se na autonomia, na liberdade e no convívio social, e afetam não apenas a frequência, mas também a qualidade dos relacionamentos interpessoais e dos vínculos afetivos no grupo. Neste cenário, tornam-se importantes as ações educativas formais ou informais, pois, ao elaborar no coletivo as questões geradoras dessa crise, o idoso tem oportunidade de se confrontar com fatos, idéias e realidades que contrastam com o cotidiano normalizador, de incorporar novas atitudes diante do envelhecimento, da velhice e da própria vida, de (re)encontrar-se e (re)edificar sua própria identidade. Neste aspecto, a identidade individual, intimamente associada à identidade social, reforça a importância das relações com os outros e com o mundo, como oportunidade de ressignificação da sua auto-imagem e da sua auto-estima [Santana e Sena, 2003 apud Gáspari e Schwartz, 2005].

Outro aspecto a ser destacado, quando pensamos em ações educativas dirigidas aos idosos, se situa no campo da ciência cognitiva, que se define pelo estudo da mente e do conhecimento em todas as suas manifestações. Na década de 1940, nos Estados Unidos, foi formado um grupo interdisciplinar para estudar a mente e a cognição. Desde então, as neurociências não pararam de se desenvolver e de revelar aspectos inéditos do funcionamento cognitivo do ser humano. A interdisciplinaridade converge hoje para cinco disciplinas: neurociência, psicologia cognitiva, inteligência artificial, linguística e filosofia. A atual abordagem dessa ciência entende o processo cognitivo como uma construção do mundo, dinâmica e inseparável do histórico de vida. A cognição é uma construção resultante da interação do homem com o seu mundo [Lima, 2001b] isso significa que não somos passivos diante do mundo e que nós o percebemos a 
Dossiê Temático:

Cultura, Civilização e Cidadania

medida que o construímos e enquanto somos por ele construídos. Trata-se, portanto, de um processo dialógico. Nesse processo de interação são produzidos significados compartilhados, não se excluindo os sentimentos, as emoções e a dimensão histórica. Todos esses fatores têm efeito sobre a cognição.

Os referenciais científicos da ciência cognitiva direcionados para o envelhecimento nos proporcionam novos olhares sobre a velhice no século XXI e o aumento da longevidade humana trouxe também a idéia de que um corpo vigoroso necessita de um cérebro que o acompanhe e que, com o aumento significativo da população idosa, os problemas relacionados à memória e aos riscos cerebrais podem tornar-se uma grave questão de saúde pública. A nova realidade científica está derrubando o mito de que o tamanho e o potencial do cérebro são geneticamente determinados, resultando na impossibilidade de alterar sua capacidade de funcionamento. Hoje, afirma-se que o cérebro é um órgão em constante crescimento e mudança e que sua capacidade e vitalidade dependem da forma com é nutrido e tratado. Os neurocientistas sabem que a plasticidade cerebral é surpreendente. Há 30 anos o conhecimento sobre o funcionamento do cérebro era inferido a partir do comportamento humano, mas com o surgimento da tomografia computadorizada em 1972 e, mais tarde, da tomografia por emissão de pósitrons, que gera imagens nítidas da anatomia e metabolismo cerebral, pôde-se conhecer detalhadamente a estrutura e a função do cérebro. Também as descobertas da nova biologia do cérebro provaram que as células cerebrais continuam produzindo novos dendritos e receptores, gerando novas sinapses ou junções para comunicação. Dessa maneira, a essência dos neurotransmissores que estimulam a atividade cerebral é alterada, podendo ser geradas, assim, células inteiramente novas no cérebro adulto. A composição dos neurotransmissores e a bioquímica funcional dos receptores mudam constantemente e parte dessa mudança depende do que ingerimos e do que fazemos. Daí pode-se afirmar que os alimentos e o estilo de vida, incluindo exercícios físicos e mentais, afetam diretamente o funcionamento do cérebro. [Lima, 2001b]

Portanto, duas noções básicas sobre a natureza do cérebro, antes consideradas certezas, estão sendo negadas: a de que o cérebro pára de crescer e de se modificar após a infância e a de que o cérebro perde constantemente células cerebrais após os vinte anos e, consequentemente, ocorre um declínio inevitável nas capacidades cerebrais. Acreditavase, então, que na velhice o cérebro perdia a capacidade de crescer e que $40 \%$ das suas células poderiam ser destruídas. Sendo assim, todas as pessoas perderiam necessariamente a memória e teriam sua capacidade cerebral reduzida. Isso significava senilidade para todos que chegassem à velhice. $\mathrm{Na}$ verdade, não se deve confundir senilidade, um estado patológico, com senescência, um estado normal de envelhecimento. Dessa forma, hoje, já partimos da premissa de que o declínio cognitivo não é uma parte normal do envelhecimento e, daí, pode-se afirmar que o estímulo mental contínuo proporciona uma memória melhor, permitindo-nos pensar melhor.

Além dos aspectos biológicos da memória, é necessário chamar atenção para a memória enquanto fenômeno social, pois só nos lembramos porque os outros e a situação por nós vivida, no presente e em confrontação com os outros, nos faz lembrar. Nossa tarefa de relembrar será tanto mais frutífera quanto maior for sua relevância para a sociedade. Propor aos idosos um maior envolvimento com a educação significa ultrapassar um simples processamento mecânico da torrente de informações que, no presente, 
Dossiê Temático:

Cultura, Civilização e Cidadania

apenas saturam a fome de conhecer. O que os velhos lembram não significa apenas mais informações, mas expressa riqueza e diversidade, não se reduzindo a critérios de eficiência e utilidade. [Bartholo, 2003]

Com todas as novas possibilidades podem-se considerar mais seriamente os efeitos da educação na população idosa, lhe proporcionando uma melhor qualidade de vida. E colocam-se, consequentemente, as questões: Como levar o idoso para a escola? Ele conhece essa possibilidade? Ele se conhece, sente a necessidade de buscá-la? Os resultados das universidades abertas para idosos nos mostram que há uma transformação considerável quando o idoso tem acesso ao saber. Porém, somente os projetos que não se limitam a dar informações, mas priorizam a problematização de situações, têm efeitos transformadores. A problematização se dá a partir das reais necessidades de sua vivência, fazendo-o refletir, ponderar, aprender a analisar e a encontrar soluções. Voltar à escola abre a possibilidade de reformar o pensamento dos idosos para que eles reformem a velhice que vivenciam. Tanto no âmbito internacional, quanto no nacional e local, as consequências das projeções do crescimento populacional feitas para as próximas décadas são complexas e não permitem mais a isenção de responsabilidade social. A isto se relaciona a crescente preocupação dos diversos campos do conhecimento humano com os assuntos direta e indiretamente ligados ao prolongamento das experiências e das aprendizagens humanas. Todos os aspectos subjetivos presentes no enredo psicológico do idoso, e seus processos de ressignificação emocional em todos os âmbitos, requisitam pedagogias específicas, norteadas por uma concepção de educação permanente ou continuada, isto é, que prossegue ao longo de toda a vida, escolarizada ou não. [Gáspari e Schwartz, 2005]

Dessa forma, os determinantes demográficos, culturais e econômicos tornam a questão do idoso extremamente relevante para a sociedade como um todo, donde políticas dirigidas especificamente para este segmento etário devem ser implementadas com urgência. Modelos inovadores de atenção, como os centros de convivência, têm-se revelado alternativas com resultados encorajadores e as universidades podem oferecer, dentro da concepção de microuniversidades temáticas, um modelo de centro de convivência ampliado, como as Universidades da Terceira Idade, como um campo de experimentação e assistência integralmente voltado para os desafios da terceira idade. [Veras e Caldas, 2004] Com a tendência de crescimento do envelhecimento populacional, que está acarretando mudanças profundas em todos os setores da sociedade, o atendimento das demandas geradas por esse crescimento implica a necessidade de planejamentos criteriosos e adequados a uma nova realidade. Neste sentido, o tema se reveste de especial relevância como objeto de estudo, pois se torna cada vez mais necessário conhecer as causas e os modos desse crescimento, assim como as necessidades e as condições de vida da população idosa. 


\section{Referências}

Baca, E. (1997) Depresión: calidad de vida y depresión. Revista Clínica Española, 197 (3): 48-55.

Baltes, M.; Silvenber, G. S. (1995) A dinâmica dependência-autonomia no curso da vida. In: NÉRI, A. L. (Org.) Psicologia do envelhecimento. Campinas: Papirus, cap.3.

Bartholo, M. E. (2003) No último degrau da vida. Revista do Mestrado em História da USS, Vassouras, v.5, p.128.

Bobes, J.; Cervera, S.; Seva, A. (1995) Calidad de vida y trastornos depresivos. Sevilla: Congreso Nacional de Psiquiatría.

Bosq, M. (2001) Calidad de v ida. Dedicado al desarrollo de la calidad de vida y la productividad personal. Internet.

Braga, P. M. V. (2004) Direitos do idoso. São Paulo: Quartier Latin.

Brasil. Presidência da República. Casa Civil. Subchefia para Assuntos Jurídicos. (2003) Estatuto do idoso. Lei no 10.741. Brasília.

CIA. The world factbook (2009). Disponível em: https://www.cia.gov/library/ publications/the-world-factbook/fields/2102.html. Acesso em: 17.05.2010.

Côrte, B.; Mercadante, E.; Arcuri, I. (Orgs.) (2005) Velhice, envelhecimento, complex(idade). São Paulo: Vetor.

Dantas, R. A. S.; Sawada, N. O.; Malerbo, M. B. (2003) Pesquisa sobre qualidade de vida: revisão da produção científica das universidades públicas de São Paulo. Revista Latino-americana de Enfermagem, 11(4):532-8, jul.-ago.

Debert, G. G. (2004) A reinvenção da velhice. São Paulo: EDUSP.

Dias, M. I. C. (2005) Envelhecimento e violência contra os idosos. Sociologia, Faculdade de Letras do Porto, n.15, p.249-273.

Diogo, M. J. D.; Néri, A. L.; Cachioni, M. (Orgs.) (2004) Saúde e qualidade de vida na velhice. Campinas: Alínea. Coleção Velhice e Sociedade.

ferrigno, j. c. (2004) Co-educação entre gerações. São Paulo: Vozes.

Fogaça, M. C. C. B. H. (2001) Reflexões sobre o envelhecimento. São Paulo: LTr.

Gáspari, J. C.; SCHWARTZ, G. M. (2005) O idoso e a ressignificação emocional do lazer. Psicologia: Teoria e Pesquisa, v.21, n.1, p.69-76, Abr.

Kachar, V. (2001) Longevidade: um novo desafio para a educação. São Paulo: Cortez.

Lima, M. P. (2001a) Gerontologia educacional. São Paulo: LTr.

. (2001b) Reformas paradigmáticas na velhice do século XXI. In KACHAR, V. Longevidade: um novo desafio para a educação. São Paulo: Cortez. 
Lucas, R. (1998) Versión española del WHOQOL: Calidad de Vida, Proyectos de Investigación, Cuestionarios. Ginebra: División de Salud Mental de la OMS.

Monteiro, P. P. (2001) Envelhecer - histórias, encontros, transformações. Belo Horizonte: Autêntica.

Oliveira, J. C.; ALBUQUERQUE, F. R. P. C.; LINS, I. B. (2004) Projeção da população do Brasil por sexo e idade para o período 1980-2050 - Revisão 2004. Rio de Janeiro: IBGE - Diretoria de Pesquisas - DPE. Coordenação de População e Indicadores Sociais - COPIS.

Oms - Organização Mundial de Saúde. (2001) The world health report. Genebra.

Pereira, R. J. et al. (2006) Contribuição dos domínios físico, social, psicológico e ambiental para a qualidade de vida global de idosos. Revista de Psiquiatria do Rio Grande do Sul, v.28, n.1, p.27-38, abr.

Qualidade de Vida. (2002) Disponível em: http://www.saude.sc.gov.br/sala_de leitura. Acesso em: 14 set.

Sousa, L.; Galante, H.; Figueiredo, D. (2003) Qualidade de vida e bem-estar dos idosos: um estudo exploratório na população portuguesa. Revista de Saúde Pública, São Paulo, v.37, n.3.

United Nations. (2007) The Department of Economic and Social Affairs. Population Division. World population prospects: the 2006 revision - highlights. New York.

Vázquez-Varquero, J. L. et al. (1998) Psiquiatría en atención primaria. In BACA, E. Repercusiones de la enfermedad mental sobre la calidad de vida. Madrid: Aula Médica.

Veras, R. P.; Caldas, C. P. (2004) Promovendo a saúde e a cidadania do idoso: o movimento das universidades da terceira idade. Ciência e saúde coletiva, v.9, n.2, p.423-432, Jun.

Whoqol - Instrumentos de avaliação de qualidade de vida. Versão em português: 1998. Disponível em: <http://www.ufrgs.br/psiq/whoqol>. Acesso em: 14 set. 2002.

Xaviera, F. M. F.; Feraz, M. P. T.; Marc, N. et al. (2003) A definição dos idosos de qualidade de vida. Revista Brasileira de Psiquiatria, v.25, n.1, p.31-39, mar. 